\title{
Preferences:
}

Format: Oral (but poster presentation is fine too)

\section{A New Look at Subjective Rhythmisation}

\author{
Rasmus Bååth \\ Lund University Cognitive Science \\ rasmus.baath@lucs.lu.se
}

Keywords: meter; subjective rhythmisation

\section{INTRODUCTION}

Subjective rhythmisation (SR) is the phenomenon that when presented with a sequences of isochronous, identical sounds one can experience a pattern of accents that groups the sounds, often in groups of two, three or four [1]. SR has been explained using a model of rhythm perception based on neural oscillation [3]. The present study aims at extending the scope of earlier studies by including sequences from a wider range of inter stimuli intervals (ISI). A second aim is to investigate how perceived grouping relates to tempo, measured as the sequence inter stimulus interval (ISI). Using a simple model of neural oscillation as a starting point gives that the relation between grouping and ISI should follow a power-law distribution where grouping $=c \cdot I S I \beta, c$ and $\beta$ being constants with $\beta$ being negative.

\section{METHOD}

Nine female and 21 male participants, ranging in age from 19 to 78 years $(M=31.6, S D=12.8)$ were recruited from the Lund community. The participants were seated in front of a computer wearing head phones. The task consisted of 32 click sequences of different tempo presented in a random order. The ISIs of the sequences were 150, 200, 300, 600, 900, 1200, 1500 and $2000 \mathrm{~ms}$. For each sequence the participants were to indicate if they felt a grouping of the clicks on a scale ranging from "No grouping/groups of one" to "Groups of eight". An online version of the the task can be found at http://www.sumsar.net/files/sr_task/ public_sr_task.html.

\section{RESULTS}

All participants managed to carry out the task and for all participants but one, there was a significant negative correlation between ISI and perceived grouping. The participant that showed no significant correlation is not included in the subsequent analysis. Figure 1 shows the distribution of the probability of perceiving a grouping as a function of ISI. Groupings of five, six and seven are not included as they accounted for only $3 \%$ of the reported groupings. Figure 2 shows a log-log plot of the mean of perceived grouping as a function of ISI. The superimposed line shows the linear regression fit of the log-transformed data $\left(\beta=-0.52, \mathrm{R}^{2}=0.63\right.$, $\mathrm{p}<0.001)$.
Figure 1: The probability of perceiving a grouping by ISI.

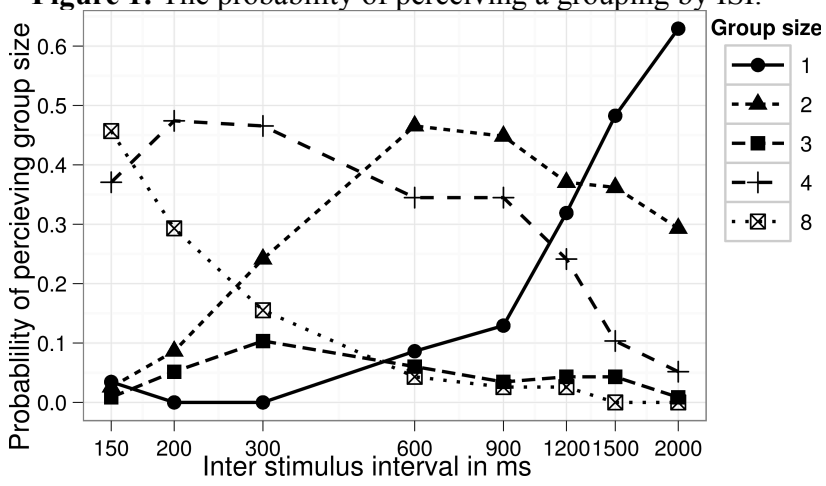

Figure 2: Mean grouping by ISI. The line ranges show the standard error.

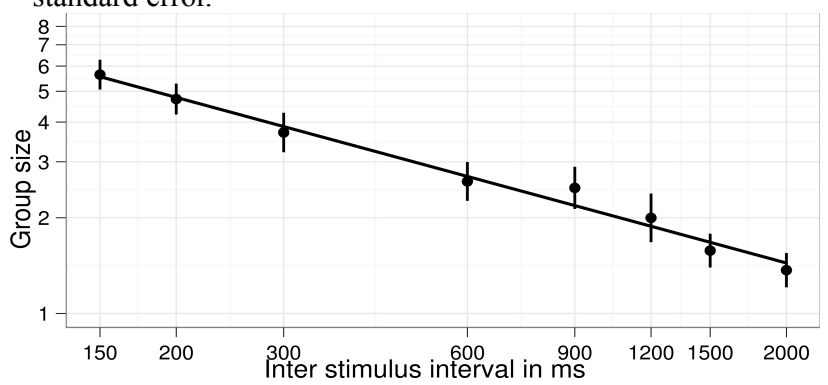

\section{DISCUSSION}

This study replicates two of the findings of earlier SR studies, that is, percieved grouping tend to increase as ISI decreases and even groupings are much more common than odd. From ISI $900 \mathrm{~ms}$ to $2000 \mathrm{~ms}$ there is a steep increase in the probability to perceive no grouping, with a peak probability of $63 \%$ at ISI $2000 \mathrm{~ms}$. This is in accordance with the notion of there being an upper limit to subjective rhythmisation but is discordant with an often proposed upper limit in the range of ISI $1500 \mathrm{~ms}$ to 2000 ms [2]. A power-law distribution appears linear on a loglog plot. Figure 2 shows an approximately linear relation and support the prediction, given by a simple model based on neural oscillation, that the relation between grouping and ISI follows a power-law distribution.

\section{REFERENCES}

[1] Vos, P. (1973). Waarneming van metrische toonreeksen. Nijmegen: Stichting Studentenpers.

[2] Fraisse, P. (1982). Rhythm and tempo. The psychology of music, 149-180.

[3] Large, E. W. (2008). Resonating to musical rhythm: Theory and experiment. The psychology of time, 189231. 